\title{
Collegiate Trainees Committee report on career guidance in psychiatric training
}

\author{
R.F. Kehoe, E. Guthrie and A. Haggith
}

\begin{abstract}
To defermine the avallability of career guidance within psychlatric training, the Collegiate Trainees Committee surveyed 300 trainees who had recently sat the MRCPyych Part II examination and 136 (45\%) responded. Most trainees had recelved little or no career guidance and some had sought career advice without success. One third of trainees felt they had encountered discrimination within their peychiatric training. We urge trainees to be pro-active in seeking career guidance, identtly sources of advice and make suggestions for topics to be discuseed within consultant supervision sessions. We recommend that local access to career advice should be assessed by visting College inspection panols.
\end{abstract}

It is well recognised that some medical schools produce proportionally more career psychiatrists than other schools. Several studies have considered some of the factors which may contribute these differences - student selection, attitude of teachers, and model of psychiatry (Brook, 1976; 1983). Little has been reported, however, about the factors which determine choice of specialty within psychiatry once a doctor has entered psychiatric training, or about the role of career advice imparted to trainees. Career guidance is one of the issues that should be discussed in the trainee's weekly supervision session with his or her consultant, in the latter's role as educational supervisor. Wider arrangements, beyond local training schemes, were outlined by Johnson (1990) and relate to recommendations made by the Conference of Postgraduate Medical Deans of the United Kingdom. Despite these arrangements, and following discussion within the Collegiate Trainees Committee of the Royal College of Psychiatrists (CTC) and with audiences at the local trainees' days that it organises, it was apparent that trainees themselves were concerned about the availability of career guidance. Furthermore, CTC representatives have relayed concern about trainees in their local areas who have been 'stuck' at the registrar level and who have, or are contemplating leaving psychiatry altogether. The CTC wished to determine the amount of career advice that relatively experi- enced psychiatric trainees had obtained, their career aspirations within psychiatry, and any particular difficulties they have encountered within their training.

To assess the size of this problem we surveyed a group of trainees who one would have expected to have received some career advice or guidance-those who had recently sat the MRCPsych Part II examination.

\section{The study}

Three hundred questionnaires were distributed to trainees with British addresses from the College examinations office along with their examination results. One hundred questionnaires were sent initially to those who passed the examination in December 1991 and 48 responded. To obtain a larger sample, a further 200 questionnaires were distributed to those who sat the examination in May 1992 (and passed or failed) and 88 replied. This gave a total of 136 (45\%) responses. Replies were anonymous as we wished to obtain information on a strictly confidential basis. We initially asked only those who passed the examination as we thought it more likely that they would respond, but we then recognised the need for a larger sample size. Trainees were asked about formal career advice (presentations, courses, meetings with regional advisers) and informal advice (in supervision, with colleagues, discussion in corridor).

\section{Findings}

The mean age of the sample was 31 years (range 28-50 years) and $62(46 \%)$ were female. They had qualified in medicine an average of 6.6 years previously and had trained in psychiatry an average of 4.3 years (range 3-10 years).

\section{Career aspirations}

Seventy-nine (51\%) had firm intentions about working in one (or more) specialty within 
Table 1. Career specialty interest for those trainees who expressed a preference $(n=128)$

\begin{tabular}{lll}
\hline Specialty & $\begin{array}{l}\text { Number of trainees } \\
\text { expressing interest }\end{array}$ & $\begin{array}{l}\text { Percentage of trainees } \\
\text { expressing interest }\end{array}$ \\
\hline General psychiatry & 72 & 53 \\
Child \& adolescent & 39 & 29 \\
Old age psychiatry & 32 & 24 \\
Liaison psychiatry & 33 & 24 \\
Community psychiatry & 29 & 21 \\
Psychotherapy & 23 & 17 \\
Forensic psychiatry & 22 & 16 \\
Alcohol/substance misuse & 18 & 13 \\
Learning difficulties & 10 & 7 \\
\hline
\end{tabular}

psychiatry, $49(34 \%)$ were unsure, five $(4 \%)$ had no idea about their preferred career direction and three made no response. Table 1 illustrates the specialties in which those trainees who declared one or more particular interests wished to pursue a career; 45 named only one speciality area, 40 two, 27 three, 8 four and 8 trainees identified five areas of potential interest. Eight trainees made no response or had no idea of their future areas of interest. Trainees were not asked to rank their preferences.

Six $(4 \%)$ trainees had developed their particular interest before undergraduate training, 20 (15\%) before entering psychiatry, 24 (18\%) before and $78(58 \%)$ after working in that specialty. Most trainees had aspirations to obtain a consultant or academic post, but eight $(6 \%)$ wished to acquire a staff grade post and three intended to leave psychiatry.

\section{Career guidance}

One hundred and two (76\%) trainees had not received any formal career guidance, $25(19 \%)$ a little, seven (5\%) a moderate amount, and none had received a great deal of formal guidance. Ninety-eight $(73 \%)$ trainees felt that they had received little or no career advice (informal or formal), and $36(27 \%)$ a moderate amount or a great deal of advice. Two trainees made no response to these questions. When advice had been given, it came from a consultant (55\%), peers $(18 \%)$, psychiatric tutor $(15 \%)$ or senior registrar $(11 \%)$. Twenty-one $(16 \%)$ trainees stated that they had sought, but had been unable to acquire specific career advice.

Most respondents had indicated their career intentions and $69(51 \%)$ considered that they were well-informed with respect to future prospects within those specialties. Twenty-four (18\%) admitted to knowing nothing about the College's training requirements for their specialty of interest.

\section{Difficulties in training}

We also asked about any particular difficulties that trainees had experienced within their psychiatric training. Ten $(7 \%)$ described racial discrimination, $13(10 \%)$ sexual discrimination and $13(10 \%)$ had experienced interpersonal problems with a particular consultant. A further 24 $(18 \%)$ described other difficulties, especially in balancing domestic commitments with training requirements, obtaining part-time employment. and in several cases feeling discriminated against because of the potential of future maternity leave. Seven $(5 \%)$ said they had run into problems getting posts because of a lack of good advice. In all, $34 \%$ of respondents felt they had experienced at least one of the above forms of discrimination within their psychiatric training.

\section{Discussion}

The conclusions of this survey are limited by the response rate to the questionnaire: the respondents may have been more likely to have had difficulties than the non-respondents. There are also the problems in defining what constitutes 'career guidance' and 'discrimination'. Here we have accepted the respondents' perception of each. Despite these limitations, our results allow us to draw the following conclusions.

(a) The distribution of intended career interests in this sample accords reasonably to the future availability of posts, with the exception of the low interest in mental handicap.

(b) Most trainees receive little or no career guidance. Many trainees are ill-informed with respect to future job prospects and College requirements for specialty training. Together with the finding that some trainees actively seek and do not obtain career advice, it demonstrates 
the need for greater avallability of career guidance.

(c) One third of psychiatric trainees feel they have encountered racial, sexual or personal discrimination within their psychiatric training.

There is a need to review the existing arrangements by which psychiatric trainees can access career advice. The CTC may be able to contribute to such deliberations and we make the following proposals.

(a) Trainees need to be more pro-active in seeking career guidance from their consultants.

(b) Consultants should be aware of the breadth of topics that need to be addressed in supervision sessions with their trainees.

(c) Career guidance should continue to be one of the topics for discussion at supervision sessions between trainee and consultant and particularly at meetings between trainee and tutor. Particular areas for discussion may include: a trainee's strengths and weaknesses; balance of training; experience of audit, management and research; areas of clinical interest: College guidelines for specialty training; long-term personal goals; job availability; preparing a curriculum vitae; consideration of part-time training; consultant post v. staff grade; health service $v$. academic or other post; and useful literature, for example the series on 'Careers in Psychiatric Specialties' in the Psychiatric Bulletin from November 1990.

(d) At Central Approval Panel visits, consultants, tutors and trainees should be asked about existing arrangements for career guidance.

(e) The possible loss of trained personnel from the service through being 'stuck' at the registrar level highlights the need for increased emphasis on career planning in the College's Inceptors' Handbook. This should state that career advice should be sought at an early stage, and be a topic for discussion within consultant supervision and tutor meetings. Trainees should be encouraged to seek further advice if necessary from the College Regional Representative for any specialty area, the Regional Adviser or the Regional Postgraduate Dean. For trainees with particular difficulties, especially concerning discrimination, a Special (Career Counselling) Committee was established in 1991 by the Royal College of Psychiatrists. Individuals are encouraged to seek help if their difficulties cannot be resolved at a local level.

(f) At senior registrar level, regular meetings with the scheme organiser and annual review meetings provide an excellent forum for discussion of future career plans.

(g) The need for greater awareness of career planning and access to advice can only be made greater following the recommendations of the recent Chief Medical Officer's report on the future of specialist medical training (Department of Health. 1993).

\section{References}

BROOK, P. (1976) Career intentions of senior registrars in general psychiatry. British Journal of Psychiatry. 128, 290-298.

- (1983) Who's for psychlatry? British Journal of Psychiatry, 142, 361-365.

DEPARTMENT OF HEALTH (1993) Hospital Doctors: Training for the Future. The Report of the Working Group on Specialist Medical Training. London. HMSO.

Johnson. R. (1990) Career advice and counselling: The development of careers advice and counselling for doctors in training. Psychiatric Bulletin. 14, 179-180.

R. F. Kehoe, E. Guthrie and A. Haggith, Working Group of the Collegiate Trainees Committee, Royal College of Psychiatrists, 17 Belgrave Square, London, SW1X 8PG 